(C) 2018 IEEE. Personal use of this material is permitted. Permission from IEEE must be obtained for all other uses, in any current or future media, including reprinting/republishing this material for advertising or promotional purposes, creating new collective works, for resale or redistribution to servers or lists, or reuse of any copyrighted component of this work in other works. 


\title{
Method to Reduce THD and Improve Efficiency in SiC Power Converter.
}

\author{
E.Fernández. V. Sala. A Paredes. L Romeral. \\ Motion Control and Industrial Applications Group (MCIA). \\ Department of Electronic Engineer, University Polytechnic Catalonia. \\ Terrassa, Barcelona, España.
}

\begin{abstract}
- this paper presents a method to reduce total harmonic distortion (THD) and improve efficiency of a topology of power converter using $\mathrm{SiC}$ devices. The method consists of two parts: the first part finds the optimum offset angle between two carrier signals that are sent to the first stage of the V-I converter and PWM modulation for the current source inverter (CSI), to reduce the total harmonic distortion in the output currents. The V-I converter transforms the voltage source of the battery into a current source for the inverter. The $\mathrm{V}$-I converter operates at 30 $\mathrm{kHz}$ and the CSI at $55 \mathrm{kHz}$ switching. The second part consists of using $\mathrm{SiC}$ devices to increase the operating range in frequency, and reduce the power losses in the devices, which will improve the efficiency of the analyzed topology. Besides, a comparative study between the SiC topology and a topology with conventional Si devices was proposed, the results of simulations analyzed the power losses and THD and compared with the purpose of validating the method proposal.
\end{abstract}

Keywords-SiC, CSI, FOC Control, Surface Mounted Permanent Magnet Synchronous.

\section{INTRODUCTION}

The use of $\mathrm{SiC}$ semiconductor devices in various studies [1],[2],[3] open new lines of investigation into these elements on developing traction systems for electric vehicles, where their application can benefit and solve various problems identified in systems using devices conventional of $\mathrm{Si}$ as it losses power, low frequency of activation and too large cooling systems [4],[5]. The SiC devices have several properties that are presented in [6], the use of these elements in power converters for working at high frequency, high temperature and reduce power losses (Fig.1) in compared with conventional Si devices, making them very interesting for application in electric traction systems.

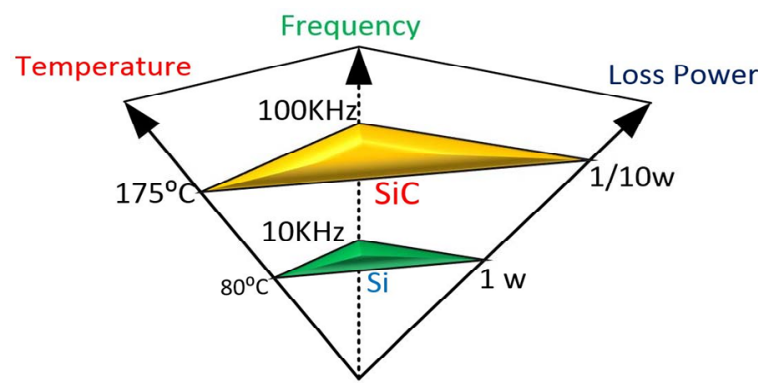

Fig 1. Comparison of work elements ranges $\mathrm{SiC}$ vs $\mathrm{Si}$.
Usually an electric traction system is formed by highvoltage battery, a power converter topology. The topology more used is the voltage source inverter (VSI) by research presented in [7]-[9], these topology incorporate a DC / DC booster. The DC / DC plays an important role in the stabilization of voltage for feeding the three-phase converter.

Nowadays, various studies present other emergent topologies [10]-[12]. In [13] the authors present the topology of CSI with a power converter V-I that controls the stabilization of the current, the input and the regeneration of the current for the battery of high voltage [13],[14]. The authors using the implementation of this topology insulated gate bipolar transistors (IGBTs) with reverse-blocking (RB) capability to low frequency of switching $(15 \mathrm{kHz}$ and 7.5 $\mathrm{kHz}$ ). The result shows that the THD is high and the technique of modulation used is the simple signals of carrier without offset angle.

Several investigations analyze and present methods to minimize losses [15], the topology most analyzed is the VSI topology but with conventional silicon devices and works to low frequency, using this devices and low frequency of switching the current are distorted and the THD increase. The method of control used in [16], extends the base speed and improves the efficiency, but they use $\mathrm{Si}$ conventional devices and the power losses are higher in the analysis they develop.

In general, in most of the literature consulted it is noted that the tendency is to develop topologies of power converters at a low frequency of operation that causes distortion in the currents, this increases the THD and losses.

The present paper contributes to search topologies of converters implemented with silicon carbide devices that work at higher switching frequencies to obtain greater efficiency and improve applications focused on electric traction systems. Besides, the implementation and the finding of the best offset angle between the carrier signals of PWM and V-I converter to obtain a reduction of THD in the proposed topology.

The paper is organized as follows: first, a study about power converter topology and methodology used to develop the proposed method are presented in section II. The operation and finding of offset angle between the carrier signals is analyzed in III. Section IV presents the study comparative of power losses of the topology with conventional devices of silicon. The results of simulation are presented in V. Finally, section VI concludes this paper. 


\section{TOPOLOGY OF POWER CONVERTER AND METHODOLOGY PROPOSED.}

\section{A) Analysis of Topology.}

The topology proposed for the analysis is presented in Fig.2. The topology uses a V-I converter to regulate the current input and a three-phase CSI that generates the threephase currents.

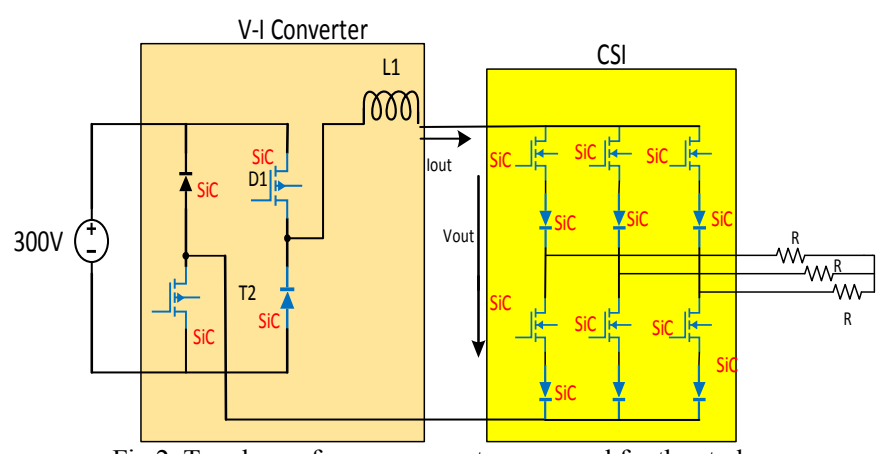

Fig 2. Topology of power converter proposed for the study.

In researches [17]-[18], it is indicated that the CSI converter as an ideal for work at high frequency, the input inductor converter would be smaller, as the filter capacitors, semiconductors $\mathrm{SiC}$ offering a high blocking voltage and low resistance state. The CSI converter has an inductor component and uses it as energy storage, in addition to certain advantages compared to the VSI topology as described in [8]-[19] as the high voltage capability, as short-circuit protection, and sinusoidal output voltage due to the effect of the output filter capacitors AC, which are much smaller in capacity.

The V-I converter has two transistors, two diodes, and an output coil, if implemented with $\mathrm{SiC}$ devices. The analysis of the modes of operation of this converter in the first place performed when the SiC MOSFET are in an ON state and then when they are in an active state OFF.

In the first state (Fig. 3) when the MOSFETs $T_{1}$ and $T_{2}$ are turned $\mathrm{ON}$ under this condition the battery voltage is applied to the converter and charging the inductor, in this mode a current $\mathrm{I}_{\text {out }}$ and a voltage $\mathrm{V}_{\text {out }}$ are obtained $\mathrm{V}_{\mathrm{S}}=\mathrm{V}$ Battery [12]. The return of the current through the activation MOSFET $\mathrm{T}_{2}$, the Diodes $\mathrm{D}_{1}, \mathrm{D}_{2}$ at this moment are in reverse bias therefore do not activate.

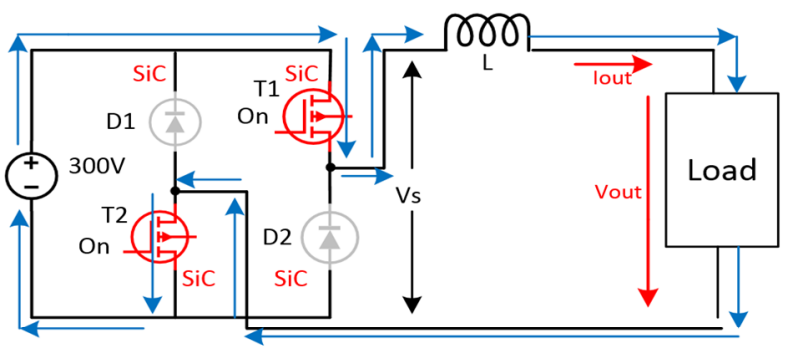

Fig.3. Converter V-I converter in the first state.
In the second state Fig. 4, the MOSFETs are turned off and the current flows through the diodes $\mathrm{D}_{1}$ and $\mathrm{D}_{2}$, this mode can be implemented in the case when the current converter returns to recharge the high voltage battery $\mathrm{Vs}=-\mathrm{V}$ Battery [11].

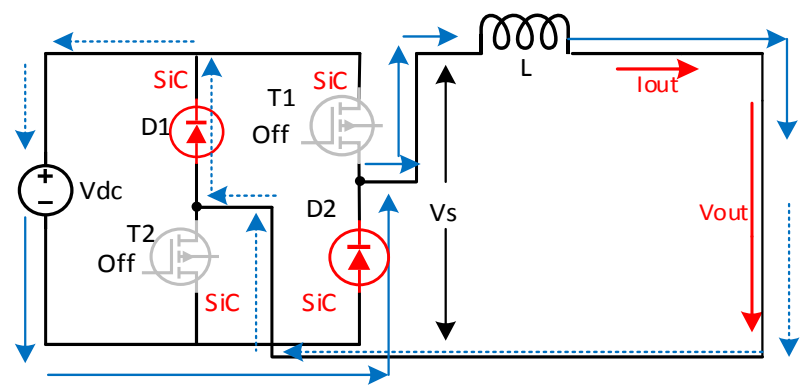

Fig 4. Topology DC/DC converter in the second state.

\section{B) Proposed Methodology}

A PWM modulation is used for the CSI and for the V-I converter. A second carrier is compared with the control PI implemented to obtain a constant current output, the main objective is to find a phase angle between the carrier signals to obtain the minimum THD in the output PWM currents, the scheme of the study proposed and the way of linking the two carrier signals is depicted in Fig.6.

The design of the control PI for the current in the V-I converter is summarized as follows: The circuit shown in Fig. 5 is a flow of current and voltage that are generated when you place a load RC. Also for the analysis considered the internal resistance of the SiC MOSFETs $\left(R_{d s}=R_{o n}\right)$, inductance $\left(R_{L}\right)$ and capacitance $\left(\mathrm{R}_{\mathrm{C}}\right)$.

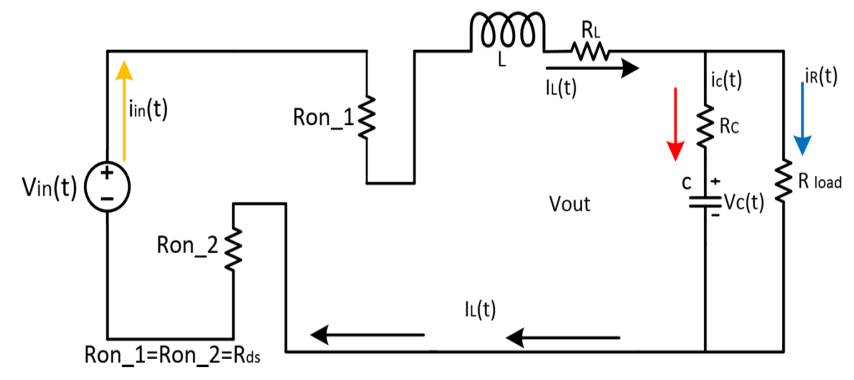

Fig 5. Analysis of DC/DC bidirectional power converter MOSFETs On.

The equations that are obtained in the function of the circuit of input shown in Fig. 7 are described as follows:

$$
\begin{aligned}
& V_{\text {in }}(t)=V_{R_{\text {on_ } 1}}+V_{L}+V_{o}+V_{R_{\text {Ron }} 2} \\
& V_{\text {in }}(t)=R_{o n_{-} 1} I_{L}(t)+L \frac{d i_{L}(t)}{d t}+R_{L} I_{L}(t)+V_{o}+R_{o n_{-} 2} I_{L}(t) \\
& V_{\text {in }}(t)=2 R_{d s} I_{L}(t)+L \frac{d i_{L}(t)}{d t}+R_{L} I_{L}(t)+V_{o} \\
& L \frac{d i_{L}(t)}{d t}=V_{\text {in }}(t)-2 R_{d s} I_{L}(t)-R_{L} I_{L}(t)-V_{o}
\end{aligned}
$$




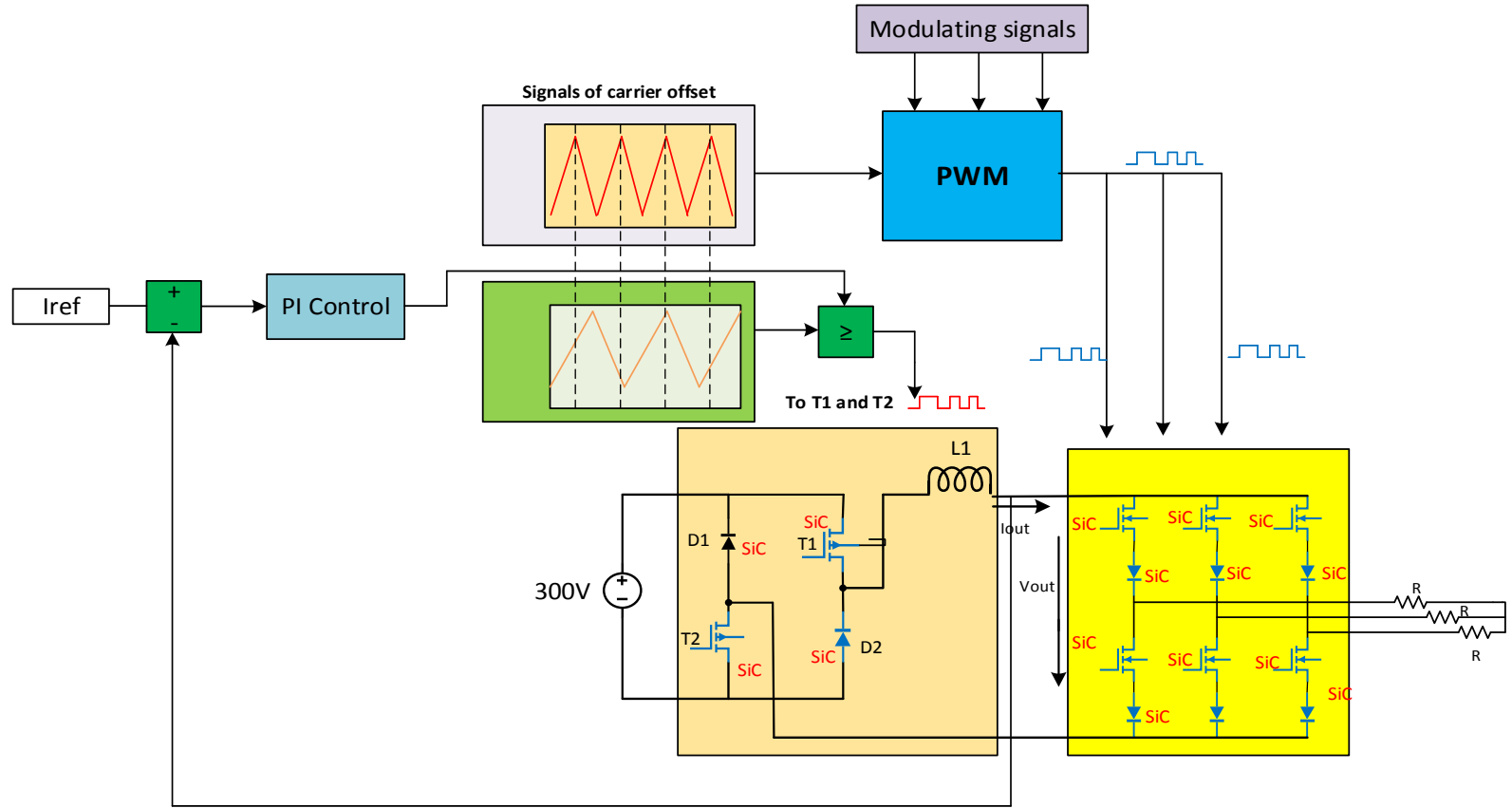

Fig 6. Schematic of operation and methodology proposed.

The value can be expressed in terms of $R_{\text {load }}$ and $R_{c}$ by the following equation:

$$
V_{o}=\frac{R_{\text {Load }} R_{C}}{R_{\text {Load }}+R_{C}} i_{L}(t)+\frac{R_{\text {Load }}}{R_{\text {Load }}+R_{C}} V_{C}(t)
$$

Substituting (5) into (4) we have:

$$
\begin{aligned}
& L \frac{d i_{L}(t)}{d t}=V_{\text {in }}(t)-2 R_{d s} I_{L}(t)-R_{L} I_{L}(t)-\frac{R_{\text {Load }} R_{C}}{R_{\text {Load }}+R_{C}} i_{L}(t)-\frac{R_{\text {Load }}}{R_{\text {Load }}+R_{C}} V_{C}(t) \\
& L \frac{d i_{L}(t)}{d t}=V_{\text {in }}(t)-\left[2 R_{d s}+R_{L}+\frac{R_{\text {Load }} R_{C}}{R_{\text {Load }}+R_{C}}\right] i_{L}(t)-\frac{R_{\text {Load }}}{R_{\text {Load }}+R_{C}} V_{C}(t)
\end{aligned}
$$$$
\frac{d i_{L}(t)}{d t}=\frac{V_{\text {in }}(t)}{L}-\left[\frac{2 R_{d s}+R_{L}+\frac{R_{\text {Load }} R_{C}}{R_{\text {Load }}+R_{C}}}{L}\right] i_{L}(t)-\frac{\frac{R_{\text {Load }}}{R_{\text {Load }}+R_{C}}}{L} V_{C}(t)
$$

The equation that is obtained from the output circuit is given by the following expression:

$$
\begin{gathered}
C \frac{d V_{C}(t)}{d t}=V(t)-i_{L}(t) \\
C \frac{d V_{C}(t)}{d t}=\frac{R_{\text {Load }}}{R_{\text {Load }}+R_{C}} i_{L}(t)-\frac{1}{R_{\text {Load }}+R_{C}} V_{C}(t) \\
\frac{d V_{C}(t)}{d t}=\frac{\frac{R_{\text {Load }}}{R_{\text {Load }}+R_{C}}}{C} i_{L}(t)-\frac{\frac{1}{R_{\text {Load }}+R_{C}}}{C} V_{C}(t)
\end{gathered}
$$

From equations (8) and (11), you can set the equation of state space mode or activation $\mathrm{ON}$.

$$
\begin{aligned}
& X(t)=A X(t)+B \\
& y(t)=C X(t)+D
\end{aligned}
$$

Theses equations can be expressed in the matrix form:

$$
\begin{aligned}
& {\left[\begin{array}{c}
\frac{d i_{L}(t)}{d t} \\
\frac{d V_{C}(t)}{d t}
\end{array}\right]=\left[\begin{array}{cc}
\frac{2 R_{d s}+R_{L}+\frac{R_{\text {Load }} R_{C}}{R_{\text {Load }}+R_{C}}}{L} & -\frac{R_{\text {Load }}}{R_{\text {Load }}+R_{C}} \\
\frac{R_{\text {Load }}}{\frac{R_{\text {Load }}+R_{C}}{C}} & -\frac{1}{\frac{R_{\text {Load }}+R_{C}}{C}}
\end{array}\right]\left[\begin{array}{c}
i_{L}(t) \\
V_{C}(t)
\end{array}\right]+\left[\begin{array}{c}
\frac{1}{L} \\
0
\end{array}\right] V_{\text {in }}(t)} \\
& {\left[\begin{array}{c}
\frac{V_{o}(t)}{d t} \\
I_{\text {in }}(t)
\end{array}\right]=\left[\begin{array}{cc}
\frac{R_{\text {Load }} R_{C}}{R_{\text {Load }}+R_{C}} & \frac{R_{\text {Load }}}{R_{\text {Load }}+R_{C}} \\
1 & 0
\end{array}\right]\left[\begin{array}{c}
i_{L}(t) \\
V_{C}(t)
\end{array}\right]+\left[\begin{array}{l}
0 \\
0
\end{array}\right] V_{\text {in }}(t)}
\end{aligned}
$$

With this system, we can proceed to calculate the transfer function of the output current with respect to the input.

The modulation used in the CSI power converter is the simple PWM with logic mapping digital circuit and the schematic of the implementation is presented in Fig. 7

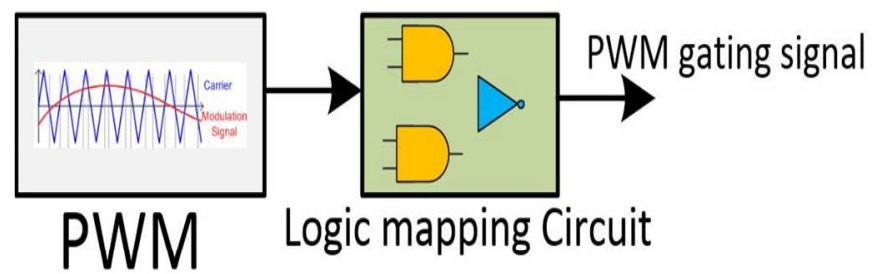

Fig 7. Technique of Modulation for CSI. 


\section{METHOD FOR FINDING THE ANGLE OfFSET OPERATION}

This section presents the stages of development to get the angle of offset between the two signals of carrier. The frequency of CSI power converter is fixed to $55 \mathrm{kHz}$. The V-I power converter is tested in values every $5 \mathrm{kHz}$ up to the maximum $(55 \mathrm{kHz})$. Simultaneously the angle of offset between the carriers' signals is increased every 10 degrees until reaching the 100 degrees of offset. For each angle and value of frequency a result of THD in PWM is obtained.

The goal is to analyze all the results obtained by determining a zone where the lowest THD PWM is obtained. The offset angle is moved to different frequencies until the maximum angle offset. Fig 8 shows some examples of the signal carrier.

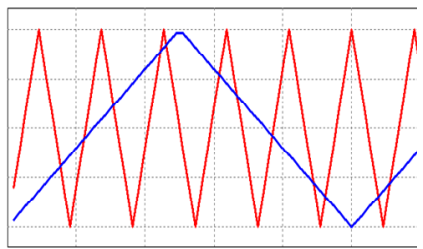

a)

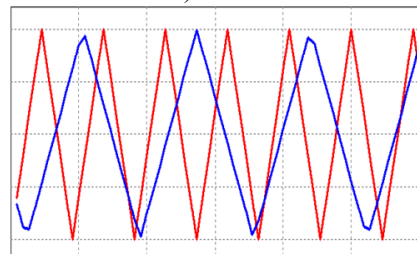

c)

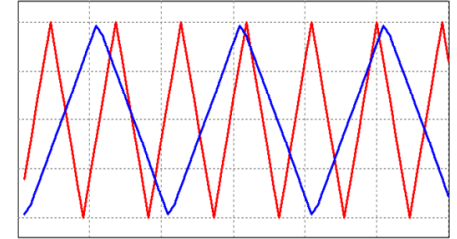

b)

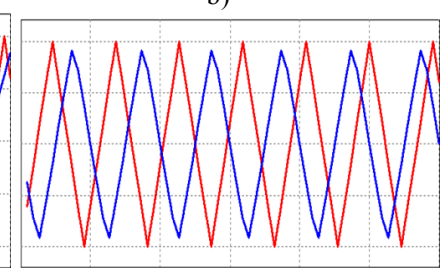

Fig 8. Signals carriers to different frequencies and angles. a) $\mathrm{Fcsi}=55$ $\mathrm{kHz}, \mathrm{Fv}-\mathrm{i}=10 \mathrm{kHz}$, angle $=0^{\circ}$; b) $\mathrm{Fcsi}=55 \mathrm{kHz}, \mathrm{Fv}-\mathrm{i}=25 \mathrm{kHz}$, angle $=20^{\circ}$; c) $\mathrm{Fcsi}=55 \mathrm{kHz}, \mathrm{Fv}-\mathrm{i}=30 \mathrm{kHz}$, angle $=50^{\circ}$; d) $\mathrm{Fcsi}=55 \mathrm{kHz}, \mathrm{Fv}-\mathrm{i}=50 \mathrm{kHz}$, angle $=90^{\circ}$.

The results obtained from THD by simulation between all the frequency ranges and angles are presented in Fig.9a and represents the different values of THD obtained and are analyzed on a surface. To determine the value of each point where the THD is minimum, the contour of the analyzed surface is used (Fig.9b).

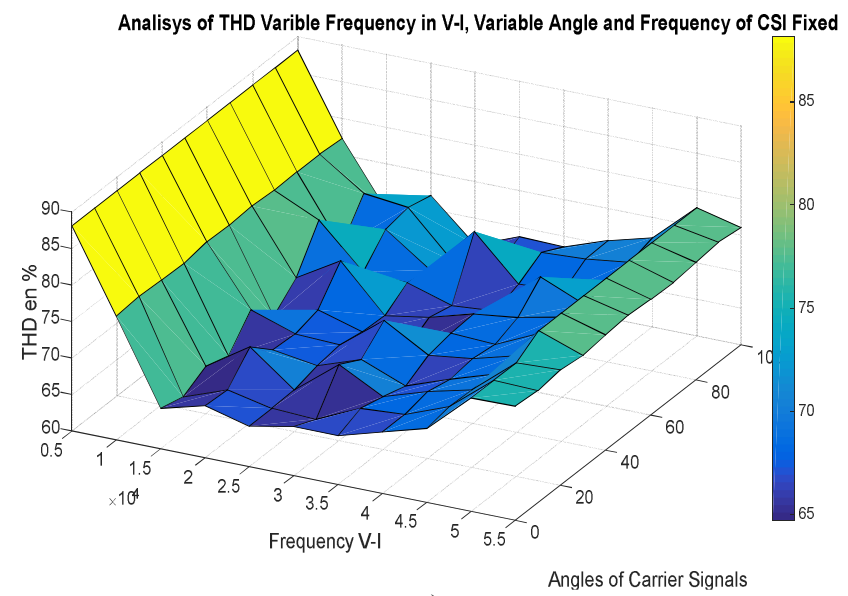

a)

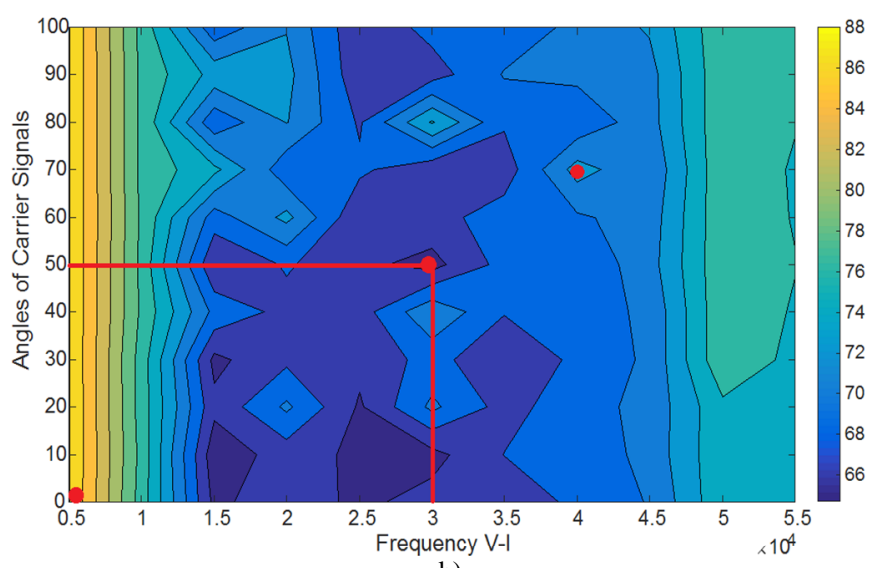

b)

Fig 9. Results of analysis. a) Surface with results of THD, b) Countour to determine the values of angle and frequency with lower THD

Select the zone where the V-I converter has the minimum THD and the angle of operation (30 kHz and 50 grades), this zone must have the highest switching frequency since it is working with $\mathrm{SiC}$ devices. In the map, there are other areas where the THD is low but found at low switching frequencies. The objective is to select the zone with the highest switching frequency. To validate the data, we select three points of the map and obtain the results shown in Table I and Fig. 10.

Table I

Analysis of differents points

\begin{tabular}{cccc}
\hline \hline $\mathbf{F}_{\text {V-I }}$ & F csi & Angle & THD PWM \\
\hline $5 \mathrm{kHz}$ & $55 \mathrm{kHz}$ & $0^{\circ}$ & $82.98 \%$ \\
$30 \mathrm{kHz}$ & $55 \mathrm{kHz}$ & $50^{\circ}$ & $65.33 \%$ \\
$40 \mathrm{kHz}$ & $55 \mathrm{kHz}$ & $70^{\circ}$ & $74.37 \%$
\end{tabular}

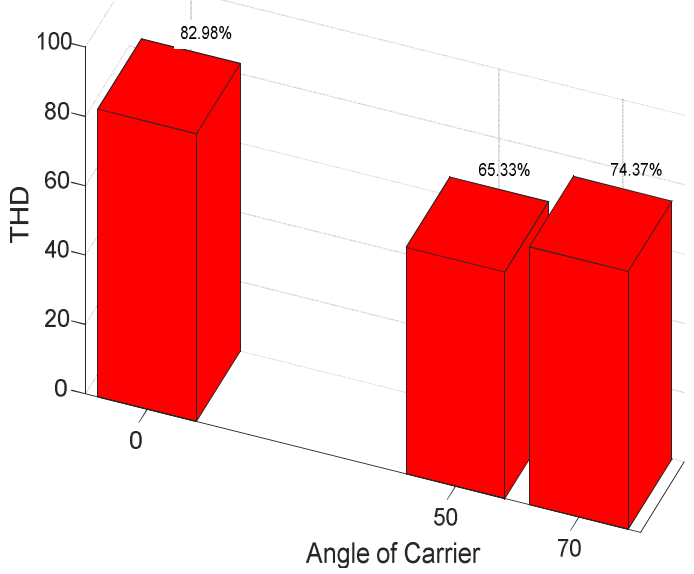

Fig 10. Results of analysis THD of three points.

From the results obtained in the analysis it can be established that by varying the angle of offset between the carrier's signals, a reduction of the THD can be obtained in the modulated output currents. The parameters, for using in the simulations, are $30 \mathrm{kHz}$ in the $\mathrm{V}$-I converter and $55 \mathrm{kHz}$ in the CSI, the angle of offset between the signal carrier is $50^{\circ}$.

\section{ANALYSIS OF POWER LOSSES AND EFFICIENCY}

For the calculation of losses in the CSI the important rule is that there must always be at least one switch forward biased 
in each half bridge of the converter [20]. The loss conduction Pc is expressed as,

Mosfet: $P_{C O N}=I_{\text {out }}{ }^{2}\left(R_{D S}\right)$

Diode: $P_{C O N}=\left(V_{T} I_{\text {out }}+R_{T} I_{\text {out }}^{2}\right)$

Where $\mathrm{V}_{\mathrm{T}}$ is the voltage threshold and $\mathrm{R}_{\mathrm{T}}$ is the dynamic resistor.

The Mosfet and diode switching power losses can be calculated with the next expression:

$P_{S W}=\frac{1}{\pi} f_{s w}\left(E_{O \eta, I}+E_{O F F, I}+E_{O F F, D}\right) \frac{V_{D C}}{i_{R E F}} \frac{I_{o u t}}{V_{R E F}}$

$V_{\text {ref }}$ and $\Gamma_{\text {ref }}$ are the DC voltage and load current amplitude at which the switching energy losses given in the datasheet were measured.

The results of power losses in the topology proposed are presented in the Table II. The results and efficiency are compared with the same topology but with Si devices to low frequency $(10 \mathrm{kHz}$ and $5 \mathrm{kHz})$ and are shown in Fig. 11.

TABLE II

Power Losses SiC vs Si Topologies

\begin{tabular}{c|c|c}
\hline \hline Parameter & $\begin{array}{c}\text { Losses in SiC } \\
\text { Topology }\end{array}$ & $\begin{array}{c}\text { Losses in Si } \\
\text { Topology }\end{array}$ \\
\hline \hline $\begin{array}{c}\text { Conduction Mosfet }+ \\
\text { diodes CSI }\end{array}$ & $57.94 \mathrm{~W}$ & $76,39 \mathrm{~W}$ \\
\hline $\begin{array}{c}\text { Switching Mosfet } \\
\text { +diodes CSI }\end{array}$ & $23.78 \mathrm{~W}$ & $21.6 \mathrm{~W}$ \\
\hline $\begin{array}{c}\text { Conduction Mosfet }+ \\
\text { diodes V-I }\end{array}$ & $19.19 \mathrm{~W}$ & $32.99 \mathrm{~W}$ \\
\hline $\begin{array}{c}\text { Switching Mosfet } \\
\text { +diodes V-I }\end{array}$ & $18.44 \mathrm{~W}$ & $14.14 \mathrm{~W}$ \\
\hline Total Power Losses & $119.35 \mathrm{~W}$ & $145.12 \mathrm{~W}$ \\
\hline
\end{tabular}

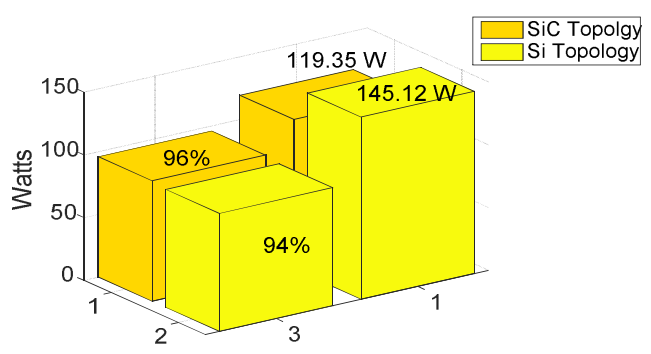

Fig 11. Power losses and efficiency in SiC Topology vs Si Topology.

Efficiency is improved and power losses in the topology with $\mathrm{SiC}$ devices are reduced. The use of this technology reduces the power losses and increases the range of operation of frequency.

\section{REsults AND Simulations.}

This section describes the different results obtained in simulation made in Matlab-Simulink. The first part presents the results of PI control in the V-I converter. Next, the results obtained in the topology analyzed and a topology with silicon devices are performed. The values of THD and currents are presented and compared by validating the method proposed.
The parameters used for the simulations are presented in the table III.

In Fig.12, the results of tuning PI control in the V-I converter are shown in simulations.

TABLE III

Parameters of Simulation

\begin{tabular}{c|c|c}
\hline \multicolumn{3}{|c}{ Parameters of Simulation } \\
\hline \hline Parameter & SiC Topology & Si Topology \\
\hline \hline Power & $2.5 \mathrm{~kW}$ & $2.5 \mathrm{~kW}$ \\
\hline \hline Voltage & $300 \mathrm{~V}$ & $300 \mathrm{~V}$ \\
\hline Current of Input & $20 \mathrm{~A}$ & $20 \mathrm{~A}$ \\
\hline Inductor & $20 \mathrm{uH}$ & $200 \mathrm{mH}$ \\
\hline Devices & $19.19 \mathrm{~W}$ & $32.99 \mathrm{~W}$ \\
\hline Load & $2 \Omega$ & $2 \Omega$ \\
\hline Frequency -I & $30 \mathrm{kHz}$ & $10 \mathrm{kHz}$ \\
\hline Frequency CSI & $55 \mathrm{kHz}$ & $5 \mathrm{kHz}$ \\
\hline Offset Angle Carrier & $50^{\circ}$ & $0^{\circ}$ \\
\hline
\end{tabular}

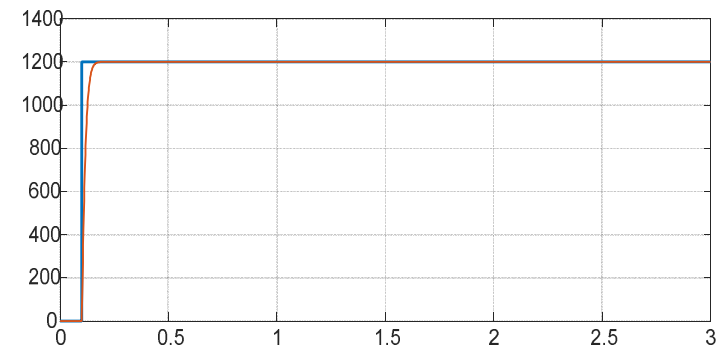

a)

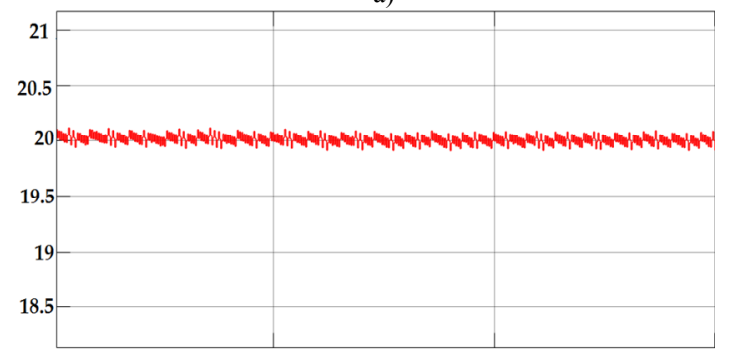

b)

Fig 12. Result of PI control in the V-I converter. a) PI tunning control; b) Current of input to CSI

The currents, waveforms, and THD comparison between the method proposed in the topology $\mathrm{SiC}$ with angle offset between carrier signals and the conventional topology with devices of silicon without angle offset are shown in Fig. 13 and Fig. 14.

\section{CONCLUSIONS}

This paper describes a method to reduce THD and improve the efficiency in SiC topology of a power converter. The proposed method shows results that by varying the angle of offset between the carrier signals a reduction of the THD can be obtained in the modulated output currents. The methodology proposed for obtained the offset angle between carrier signals and $\mathrm{Pi}$ control in the $\mathrm{V}-\mathrm{I}$ converter is convenient for this type of topology since the THD is reduced from $10.52 \%$ to $5.27 \%$, compared to the same topology but implemented with conventional silicon devices and without phase angle. The use of silicon carbide devices reduces the power losses and improves the efficiency of topology of this 
power converter in comparison with the silicon conventional and is novel for future applications in electric traction systems.

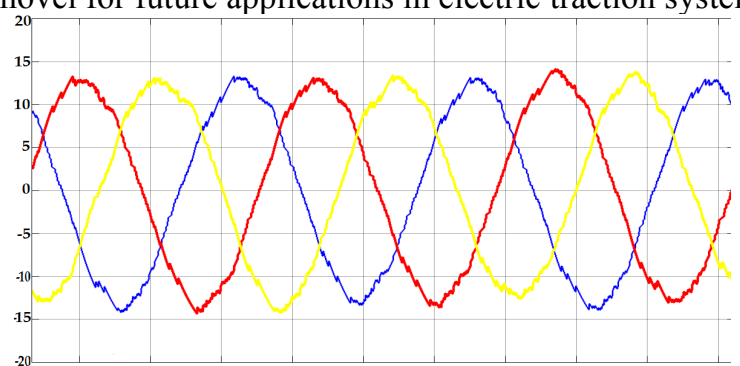

a)

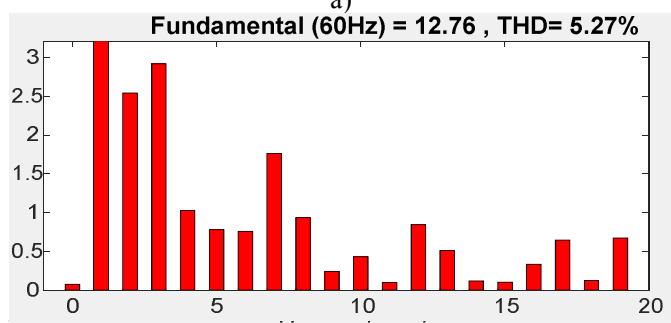

b)

Fig 12. Results in topology $\mathrm{SiC}$ with ofset angle between signal carriers . a) Currents of output; b) Anlisys of THD

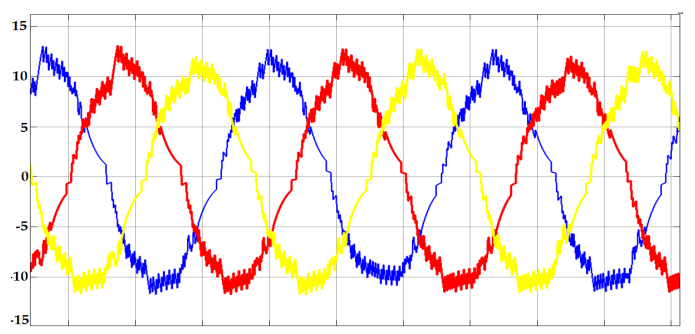

a)

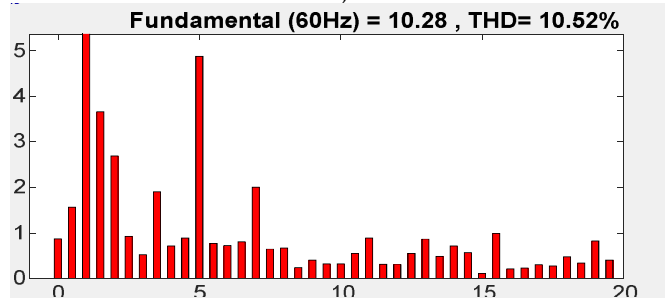

b)

Fig 12. Results in topology Si without offset angle between signal carriers . a) Currents of output; b) Analisys of THD

\section{ACKNOWLEDGMENT.}

This work was supported in part by the Spanish Ministry of Economy and Competitiveness under the TRA2016-80472R Research Project.

\section{REFERENCES}

[1] Kumar, K.; Bertoluzzo, M.; Buja, G., "Impact of SiC MOSFET traction inverters on compact-class electric car range," in Power Electronics, Drives and Energy Systems (PEDES), 2014 IEEE International Conference on , vol., no., pp.1-6, 16-19 Dec. 2014.

[2] Fei Shang; Arribas, A.P.; Krishnamurthy, M., "A comprehensive evaluation of $\mathrm{SiC}$ devices in traction applications," in Transportation Electrification Conference and Expo (ITEC), 2014 IEEE , vol., no., pp.1-5, 15-18 June 2014.
[3] Jahdi, S.; Alatise, O.; Fisher, C.; Li Ran; Mawby, P., "An Evaluation of Silicon Carbide Unipolar Technologies for Electric Vehicle DriveTrains," in Emerging and Selected Topics in Power Electronics, IEEE Journal of, vol.2, no.3, pp.517-528, Sept. 2014

[4] Wrzecionko, B.; Bortis, D.; Kolar, J.W., "A $120{ }^{\circ} \mathrm{C}$ Ambient Temperature Forced Air-Cooled Normally-off SiC JFET Automotive Inverter System," in Power Electronics, IEEE Transactions on , vol.29, no.5, pp.2345-2358, May 2014.

[5] Murakami, Y.; Tajima, Y.; Tanimoto, S., "Air-cooled full-SiC high power density inverter unit," in Electric Vehicle Symposium and Exhibition (EVS27), 2013 World, vol., no., pp.1-4, 17-20 Nov. 2013.

[6] M. Zdanowski, D. Peftitsis, S. Piasecki and J. Rabkowski, "On the Design Process of a 6-kVA Quasi-Z-inverter Employing SiC Power Devices," in IEEE Transactions on Power Electronics, vol. 31, no. 11, pp. 7499-7508, Nov. 2016.

[7] Haizhong Ye, Y. Yang and A. Emadi, "Traction inverters in hybrid electric vehicles," 2012 IEEE Transportation Electrification Conference and Expo (ITEC), Dearborn, MI, 2012, pp. 1-6.

[8] F. Xu, L. Chen and N. Narayanachar, "Traction inverter evaluation method based on driving cycles for electric and hybrid electric vehicles," 2016 IEEE Energy Conversion Congress and Exposition (ECCE), Milwaukee, WI, 2016, pp. 1-6.

[9] D. G. Woo, D. M. Joo and B. K. Lee, "On the Feasibility of Integrated Battery Charger Utilizing Traction Motor and Inverter in Plug-In Hybrid Electric Vehicles," in IEEE Transactions on Power Electronics, vol. 30, no. 12 , pp. $7270-7281$, Dec. 2015.

[10] Siwakoti, Y.P.; Fang Zheng Peng; Blaabjerg, F.; Poh Chiang Loh; Town, G.E., "Impedance-Source Networks for Electric Power Conversion Part I: A Topological Review," Power Electronics, IEEE Transactions on, vol.30, no.2, pp.699,716, Feb. 2015.

[11] Xupeng Fang; Mingjie Zhu; Zhiqiao Chen; Jie Liu; Xinwei Zhao, "Current-fed Z-source inverter modulation," in Electrical Machines and Systems (ICEMS), 2011 International Conference on , vol., no., pp.1-6, 20-23 Aug. 2011.

[12] H. Zhu, D. Yu, W. Zhu and Z. Zhou, "DC-Link Voltage Regulation of Bidirectional Quasi-Z-Source Inverter for Electric Vehicle Applications," 2016 IEEE Vehicle Power and Propulsion Conference (VPPC), Hangzhou, 2016, pp. 1-5

[13] L. Tang and G. J. Su, "Boost mode test of a current-source-inverter-fed permanent magnet synchronous motor drive for automotive applications," 2010 IEEE 12th Workshop on Control and Modeling for Power Electronics (COMPEL), Boulder, CO, 2010, pp. 1-8.

[14] Z. Wu and G. J. Su, "High-performance permanent magnet machine drive for electric vehicle applications using a current source inverter," 2008 34th Annual Conference of IEEE Industrial Electronics, Orlando, FL, 2008, pp. 2812-2817.

[15] W. Hassan and Bingsen Wang, "Efficiency optimization of PMSM based drive system," Proceedings of The 7th International Power Electronics and Motion Control Conference, Harbin, 2012, pp. $1027-$ 1033.

[16] Bharat Singh Parihar and S. Sharma, "Performance analysis of improved power quality converter fed PMBLDC motor drive," Electrical, Electronics and Computer Science (SCEECS), 2014 IEEE Students' Conference on, Bhopal, 2014, pp. 1-6.

[17] G. J. Su, L. Tang, and Z. Wu, "Extended Constant-Torque and Constant-Power Speed Range Control of Permanent Magnet Machine Using a Current Source Inverter," the 5th IEEE Vehicle Power and Propulsion Conference (VPPC'09), pp. 109-115, Sept. 7-11, 2009, Dearborn, MI.

[18] Gui-Jia Su; Lixin Tang A Current Source Inverter Based Motor Drive for EV/HEV Applications, SAE International 2011.

[19] Von Malottki, S.; Hameyer, K., "Extended base speed range by using a current-source-inverter-fed IPMSM for automotive application," in Power Electronics and Applications (EPE'14-ECCE Europe), 2014 16th European Conference on , vol., no., pp.1-8, 26-28 Aug. 2014.

[20] F. Shang, A. P. Arribas and M. Krishnamurthy, "A comprehensive evaluation of $\mathrm{SiC}$ devices in traction applications," 2014 IEEE Transportation Electrification Conference and Expo (ITEC, 2014. 